\title{
Nonlinear Effects in Multicomponent Supramolecular Hydrogels
}

\author{
Emily R. Draper, ${ }^{\dagger}$ Matthew Wallace, ${ }^{\ddagger}$ Ralf Schweins, ${ }^{\S}$ Robert J. Poole," and Dave J. Adams* ${ }^{* \dagger}$ \\ ${ }^{\dagger}$ School of Chemistry, Joseph Black Building, University of Glasgow, Glasgow G12 8QQ U.K. \\ ${ }^{*}$ Department of Chemistry, University of Liverpool, Crown Street, Liverpool L69 7ZD, U.K. \\ ${ }^{\S}$ Large Scale Structures Group, Institut Laue-Langevin, 71 Avenue des Martyrs, CS 20156, F-38042 Grenoble, CEDEX 9, France \\ "School of Engineering, University of Liverpool, Brownlow Street, Liverpool L69 3GH, U.K.
}

\section{Supporting Information}

ABSTRACT: Multicomponent low molecular weight gels are useful for a range of applications. However, when mixing two components, both of which can independently form a gel, there are many potential scenarios. There is a limited understanding as to how to control and direct the assembly. Here, we focus on a $\mathrm{pH}$-triggered two-component system. At

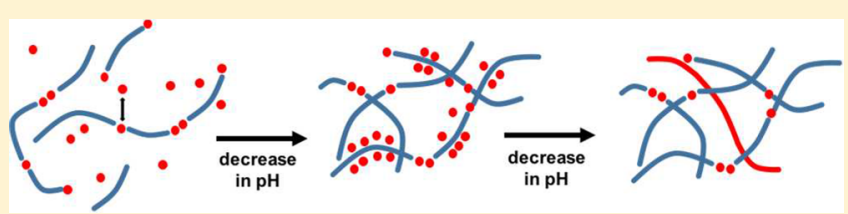
high $\mathrm{pH}$, colloidal structures are formed, and there is a degree of mixing of the two gelators. As the $\mathrm{pH}$ is decreased, there is a complex situation, where one gelator directs the assembly in a "sergeants and soldiers" manner. The second gelator is not fully incorporated, and the remainder forms an independent network. The result is that there is a nonlinear dependence on the final mechanical properties of the gels, with the storage or loss modulus being very dependent on the absolute ratio of the two components in the system.

\section{INTRODUCTION}

Low molecular weight gels have been used for a wide range of applications, including directing cell growth, optoelectronics, and controlled release. ${ }^{1-7}$ Most commonly, a single low molecular weight gelator (LMWG) is used to form the network. However, there is increasing interest in using multicomponent networks. ${ }^{8-25}$ Multicomponent self-assembled gels are a method of increasing the complexity, tuning the properties, and possibly information content into a network. $^{26-32}$ However, little is known about what properties are possible. For example, it is clear that mixing two gelators, both of which can independently lead to a gel network, can lead to either self-sorted or intimately mixed structures (Figure 1)..$^{8,9,22}$ The properties of the final gel will be controlled by the properties of the fibers that give rise to the network as well as how the fibers entangle or cross-link and how the fibers are distributed in space. Linking the gel properties to network type is not well understood for even single-component systems. There are very few reports where this is considered for multicomponent systems. Indeed, as one example, the observation that a multicomponent gel has a higher storage modulus than would be expected by simply comparing to the data for gels formed from the individual components has been used to assign gels as both self-sorted and intimately mixed. ${ }^{33,34}$

We have been investigating multicomponent hydrogels formed using $\mathrm{pH}$-responsive LMWG (example structures are shown in Scheme 1). ${ }^{34-37}$ Here, the LMWG form selfassembled aggregates at high $\mathrm{pH}$ above the apparent $\mathrm{p} K_{\mathrm{a}}$ of the terminal carboxylic acids; the structures can be spherical or wormlike micelles. ${ }^{38-40}$ This is unsurprising, as they are effectively surfactants at this elevated $\mathrm{pH} \cdot{ }^{38,41}$ As the $\mathrm{pH}$ is decreased, they start to assemble into fibrous structures at the
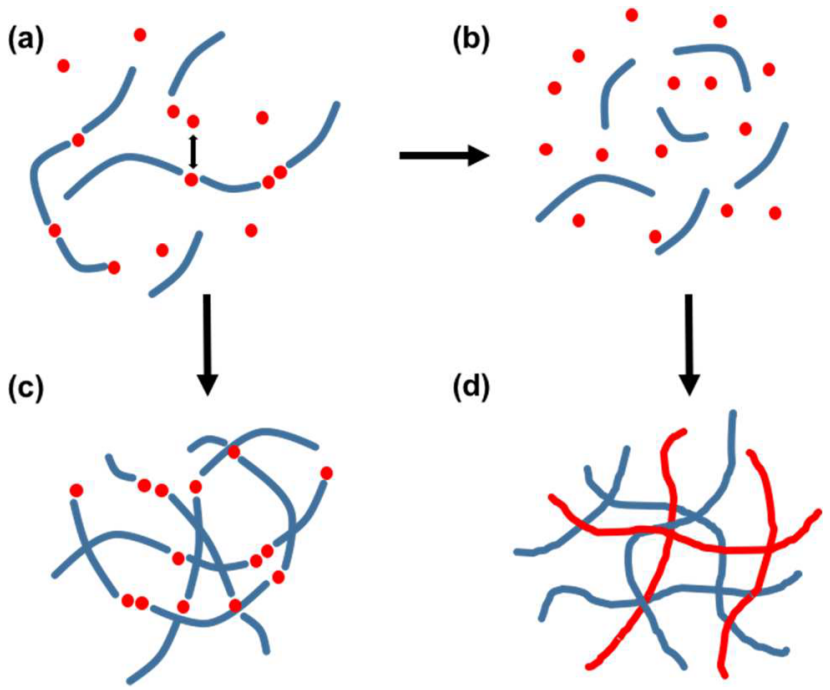

Figure 1. Cartoon showing the hypothetical assembly of two different LMWG. Either (or both) component may be assembled at high $\mathrm{pH}$ (shown here the blue LMWG forms wormlike micelles). The other component may be interacting or independent. On decreasing the $\mathrm{pH}$, there may be no interactions between LMWG (shown in (b)), meaning two independent networks form (d). Alternatively, there may be interactions between LMWG, leading to a coassembled network (c). The real situation could be somewhere between these two ideal cases.

Received: January 31, 2017

Revised: February 11, 2017

Published: February 13, 2017 
Scheme 1. Chemical Structures of 2NapFF (left) and 2NapVG (right)

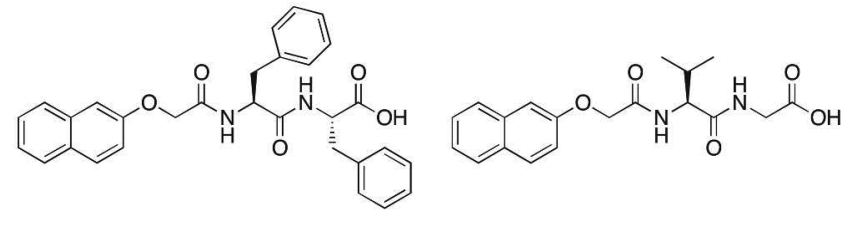

apparent $\mathrm{p} K_{a}$ which entangle and associate to form the gel network. ${ }^{42-44}$ We typically lower the $\mathrm{pH}$ slowly and controllably using the hydrolysis of gluono- $\delta$-lactone (GdL) to gluconic acid ${ }^{45}$ or the hydrolysis of an anhydride. ${ }^{46}$ These methods have proven very effective at allowing us to achieve reproducible kinetics of $\mathrm{pH}$ change and gelation.

In a mixed system, there are multiple different situations conceptually possible depending on the absolute $\mathrm{pH}$ of the system and the relative apparent $\mathrm{p} K_{\mathrm{a}}$ of the different LMWG (Figure 1). First, the self-assembled structures at high $\mathrm{pH}$ may not be affected by each other. Second, there may be mixing and perhaps even new structures formed at high $\mathrm{pH}$. Where the $\mathrm{pH}$ is decreased, assuming two independent $\mathrm{p} K_{\mathrm{a}}$ are maintained, the LMWG with the highest $\mathrm{p} K_{\mathrm{a}}$ will start to assemble into fibers first; in doing so, it will now be assembling in the presence of the second LMWG which will still have surfactantlike properties (we have previously shown that this type of LMWG can act as a surfactant ${ }^{38,41}$ ). This may fundamentally change how the first LMWG assembles, either co-operatively or disruptively. ${ }^{47}$ After the first LMWG has assembled, the second LMWG will begin to form fibers. Here, there is already a fiber network present from the first LMWG, so this may template the second LMWG, or may simply use up some of the possible space.

There is a further complication depending on the relative amounts of each LMWG in the system. It is most common to mix equal masses of each LWMG, but of course this does not have to be the case. The apparent $\mathrm{p} K_{\mathrm{a}}$ of each component can be concentration dependent, ${ }^{48}$ as can the micellar species at high $\mathrm{pH} .{ }^{38}$ Hence, this variable opens another complication to the system.

In this paper, we investigate the effect of relative concentration in a mixture of two LMWG. We concentrate on determining whether coassembly or self-sorting is occurring and on whether the structures formed at high $\mathrm{pH}$ are important in determining the gel network formed at low $\mathrm{pH}$.

\section{EXPERIMENTAL SECTION}

Materials. The $2 \mathrm{NapFF}$ and $2 \mathrm{NapVG}$ were synthesized as previously described. ${ }^{48,49}$ Deionized water was used throughout unless specified otherwise. Stock solutions were prepared by suspending the $2 \mathrm{NapFF}$ or $2 \mathrm{NapVG}$ in deionized water and then adding $1 \mathrm{~mol}$ equiv of a $0.1 \mathrm{M} \mathrm{NaOH}$ solution. The gelator dissolved in the aqueous phase over time with stirring; the $2 \mathrm{NapFF}$ typically takes overnight to fully dissolve. The $\mathrm{pH}$ of the solutions was measured at this point. To prepare the mixtures, known aliquots from the stock solutions of $2 \mathrm{NapFF}$ and $2 \mathrm{NapVG}$ were added to one another. The $\mathrm{pH}$ was checked again. To form the gels, a $2 \mathrm{~mL}$ aliquot of each solution was added to $20 \mathrm{mg}$ of glucono- $\delta$-lactone. The solution was then placed in a $7 \mathrm{~mL}$ volume Sterilin cup. This was swirled gently to allow the GdL to dissolve and then allowed to stand for $24 \mathrm{~h}$ before measurements. Rheological measurements were carried out directly in the sample tubes.

Methods. Rheology. Dynamic rheological measurements were performed using an Anton Paar Physica MCR101 rheometer. A vane and cup measuring system was used. The gels were prepared as above and loaded onto the rheometer after $24 \mathrm{~h}$. All experiments were performed at $25{ }^{\circ} \mathrm{C}$. Strain sweeps were performed from $0.1 \%$ to $1000 \%$ at a frequency of $10 \mathrm{rad} / \mathrm{s}$. The critical strain was quoted as the point that the storage modulus $\left(G^{\prime}\right)$ starts to deviate from linearity.

Shear Viscosity. A cone and plate system with a $50 \mathrm{~mm}$ cone was used to measure the viscosities of all high $\mathrm{pH}$ solutions. $2 \mathrm{~mL}$ of a solution was transferred onto the plate for measurement by pouring. The viscosity of each solution was recorded under the rotation shear rate varying from 1 to $100 \mathrm{~s}^{-1}$. All the experiments were conducted at $25{ }^{\circ} \mathrm{C}$.

Extensional Viscosity. A Capillary Breakup Extensional Rheometer ("CaBER") was used to probe the uniaxial extensional flow and comprises two circular stainless steel plattens with a diameter of $4 \mathrm{~mm}$ with an initial separation of $\sim 2 \mathrm{~mm}$. A small sample of each solution was loaded between the plattens using a syringe (without a needle to minimize the shear) to form a cylindrical sample. A rapid axial step strain is imposed $(\sim 50 \mathrm{~ms})$ until a final height $(\sim 9 \mathrm{~mm})$ is reached and an unstable filament is formed. Subsequently, the sample filament breaks up under the combined action of capillary and extensional viscoelastic forces. ${ }^{50}$

Scanning Electron Microscopy (SEM). A Hitachi S-4800 FE-SEM operating at $2 \mathrm{keV}$ was used to obtain the SEM images in deceleration mode at a distance of $3 \mathrm{~mm}$. Gel was deposited onto glass coverslips which were fixed onto aluminum SEM stubs with carbon tabs and left to dry for $24 \mathrm{~h}$. The samples were prepared by removing a small amount of the gel using a spatula, placing them on a coverslip, and allowing to air-dry. No metal was sputtered on to the sample before analysis; to minimize charging issues, deceleration mode was used.

Small-Angle Neutron Scattering (SANS). The solutions were prepared as described above, but with the $\mathrm{H}_{2} \mathrm{O}$ and $\mathrm{NaOH}$ replaced with $\mathrm{D}_{2} \mathrm{O}$ and $\mathrm{NaOD}$, respectively. The gels were prepared in UV spectrophotometer grade quartz cuvettes (Hellma) with a $2 \mathrm{~mm}$ path length. These were housed in a temperature-controlled sample rack during the measurements. SANS measurements were performed using the D11 instrument (Institut Laue Langevin, Grenoble, France). A neutron beam, with a fixed wavelength of $10 \AA$ and divergence of $\Delta \lambda / \lambda$ $=9 \%$, allowed measurements over a large range in $Q[Q=4 \pi \sin (\theta /$ $2) / \lambda]$ range of $0.001-0.3 \AA^{-1}$, by using three sample-detector distances of $1.2,8$, and $39 \mathrm{~m}$.

The data were reduced to $1 \mathrm{D}$ scattering curves of intensity vs $Q$ using the facility provided software. The electronic background was subtracted, the full detector images for all data were normalized, and scattering from the empty cell was subtracted. The scattering from $\mathrm{D}_{2} \mathrm{O}$ was also measured and subtracted from the data. Most of the data were radially averaged to produce the $1 \mathrm{D}$ curves for each detector position. However, a number of the solutions at high $\mathrm{pH}$ which were rich in $2 \mathrm{NapFF}$ exhibited shear alignment on being pipetted into the cells. Hence, the data for these were split into sectors. The instrumentindependent data were then fitted to the models discussed in the text using the SasView software package. ${ }^{51}$

NMR. NMR experiments were performed on a Bruker Avance II 400 $\mathrm{MHz}\left({ }^{1} \mathrm{H}\right)$ wide-bore spectrometer. The temperature was maintained at $25 \pm 0.5^{\circ} \mathrm{C}$, the deviation in the temperature being less than $0.1^{\circ} \mathrm{C}$. All NMR samples were prepared in $100 \% \mathrm{H}_{2} \mathrm{O}$ with $\mathrm{NaOH} .10 \mathrm{mg} /$ $\mathrm{mL}$ solutions of both gelators at $\mathrm{pH} 11$ were prepared as described above. The following compounds were then included to act as in situ $\mathrm{pH}$ indicators: sodium glycinate $(0.5 \mathrm{mM})$, disodium methylphosphonate $(0.5 \mathrm{mM})$, sodium acetate $(0.5 \mathrm{mM})$, sodium formate $(1 \mathrm{mM})$, and sodium methanesulfonate $(0.2 \mathrm{mM})$. To prepare a gel, $700 \mathrm{~mL}$ of solution was transferred to a preweighed quantity of $\mathrm{GdL}$ in a $14 \mathrm{~mL}$ vial. After gentle swirling to dissolve the GdL, the sample was transferred to a $5 \mathrm{~mm}$ NMR tube for analysis. The time shown on Figure 5 is the total time elapsed since the addition of GdL. In all cases, the integrals, NOEs, and STDs of the samples at high $\mathrm{pH}$ were recorded on the same solutions used to form the gels, shortly before the addition of GdL.

The NOE spectra of Figure 4 were acquired using a double-echo WATERGATE sequence of Liu et al. ${ }^{52}$ (Bruker library ZGGPW5). The delay between successive hard pulses in the selective pulse train 
was set at $250 \mu$ s corresponding to a $4000 \mathrm{~Hz}$ separation between the null points. Selective saturation of the methyl protons of valine was accomplished using a train of 157 Gaussian pulses during the relaxation delay $(8.1 \mathrm{~s})$, each $50 \mathrm{~ms}$ in duration with a peak power of $23 \mathrm{~Hz}$, with a separation between the pulses of $1 \mathrm{~ms}$. The signal acquisition time was set at $2 \mathrm{~s}$. The off-resonance spectra were obtained with saturation applied at $-250 \mathrm{ppm}$. Eight scans were acquired with on and off resonance saturation in an alternating manner. ${ }^{1} \mathrm{H}$ NMR spectra (Figure 5) were acquired using the same sequence but with a relaxation delay of $5.1 \mathrm{~s}$ and 98 Gaussian pulses with peak powers of $380 \mathrm{~Hz} .{ }^{1} \mathrm{H}$ NMR integrals were calculated from the off-resonance spectra and normalized to their values at high $\mathrm{pH}$ prior to the addition of GdL. The absolute integrals are plotted and are thus affected to $\leq \pm 3 \%$ by the slight retuning of the probe after the addition of GdL. When methanesulfonate was used as a reference for integration, the integrals followed the same profiles but were much noisier owing to the low concentration of the additive (data not shown). The application of saturation at $-250 \mathrm{ppm}$ does not significantly affect the gelator integrals; ${ }^{53}$ identical integrals are measured with off-resonance saturation powers of 23 and $380 \mathrm{~Hz}$ (data not shown). On resonance presaturation was applied at $-5 \mathrm{ppm}$. The saturation-transfer difference spectra, thus calculated, demonstrate a strong interaction or exchange of the NMR-visible $2 \mathrm{NapFF}$ with the assembled structures at high $\mathrm{pH}$ (Figure $\mathrm{S} 13$ ). The $\mathrm{pH}$ was calculated from the chemical shifts of the indicator compounds following our published method. ${ }^{54}$

\section{RESULTS AND DISCUSSION}

In our previous work, we have found it very difficult to ascertain whether the solutions at high $\mathrm{pH}$ contain self-sorted or mixed micellar systems. To allow us to probe the system in a number of ways, here we have chosen two specific LMWG from our extended library. 2NapFF (Scheme 1) forms wormlike micelles at high $\mathrm{pH}^{38}$ whereas $2 \mathrm{NapVG}$ (Scheme 1 ) does not. ${ }^{49}$ We hypothesized that this would allow us to easily probe the effect of mixing at high $\mathrm{pH}$, where on the basis of previous work the viscosity and small-angle neutron scattering data are expected to be dominated by the $2 \mathrm{NapFF}$.

At a concentration of $10 \mathrm{mg} / \mathrm{mL}$ and a $\mathrm{pH}$ of between 10 and $12,2 \mathrm{NapFF}$ forms a slightly turbid viscous solution. ${ }^{38}$ $2 \mathrm{NapVG}$ forms a transparent nonviscous solution at this $\mathrm{pH}$ and concentration. ${ }^{49}$ This $\mathrm{pH}$ range is significantly above the apparent $\mathrm{p} K_{\mathrm{a}}$ of both the $2 \mathrm{NapFF}$ and $2 \mathrm{NapVG}$ (6.0 and 5.0, respectively, ${ }^{48,49}$ at a concentration of $\left.5 \mathrm{mg} / \mathrm{mL}\right)$. We mixed aliquots of these solutions to provide a series of solutions with a number of different ratios of $2 \mathrm{NapFF}$ to $2 \mathrm{NapVG}$. Here, it is important that both solutions are at the same $\mathrm{pH}$; additionally, we note that for all of the following the absolute $\mathrm{pH}$ value is very important, with differences in absolute viscosity being observed depending on the $\mathrm{pH}$. Hence, for all of the data provided below for viscosities and rheological data, a single batch of each stock solution was used to generate the mixtures. The qualitative trends are the same for different $\mathrm{pH}$ between 10 and 12 , but the absolute values differ.

Mixing solutions of $2 \mathrm{NapFF}$ and $2 \mathrm{NapVG}$ such that the total concentration of LMWG was always $10 \mathrm{mg} / \mathrm{mL}$ gave translucent solutions at $\mathrm{pH} 11.0 \pm 0.2$ (N.B.: for some of the data below, $\mathrm{D}_{2} \mathrm{O}$ was used instead of $\mathrm{H}_{2} \mathrm{O}$; $\mathrm{pH}$ differs from $\mathrm{pD}$, and hence the samples in $\mathrm{D}_{2} \mathrm{O}$ were adjusted such that the $\mathrm{pH}$ was the same for all samples ${ }^{55,56}$ ). As noted above, the pure $2 \mathrm{NapFF}$ solution was visibly viscous. The viscosity of the solution decreased approximately linearly as the solution was diluted with 2NapVG (Figure 2a). This implies that the solutions are self-sorted, with the wormlike micelles present in the $2 \mathrm{NapFF}$ solution leading to the increased viscosity were
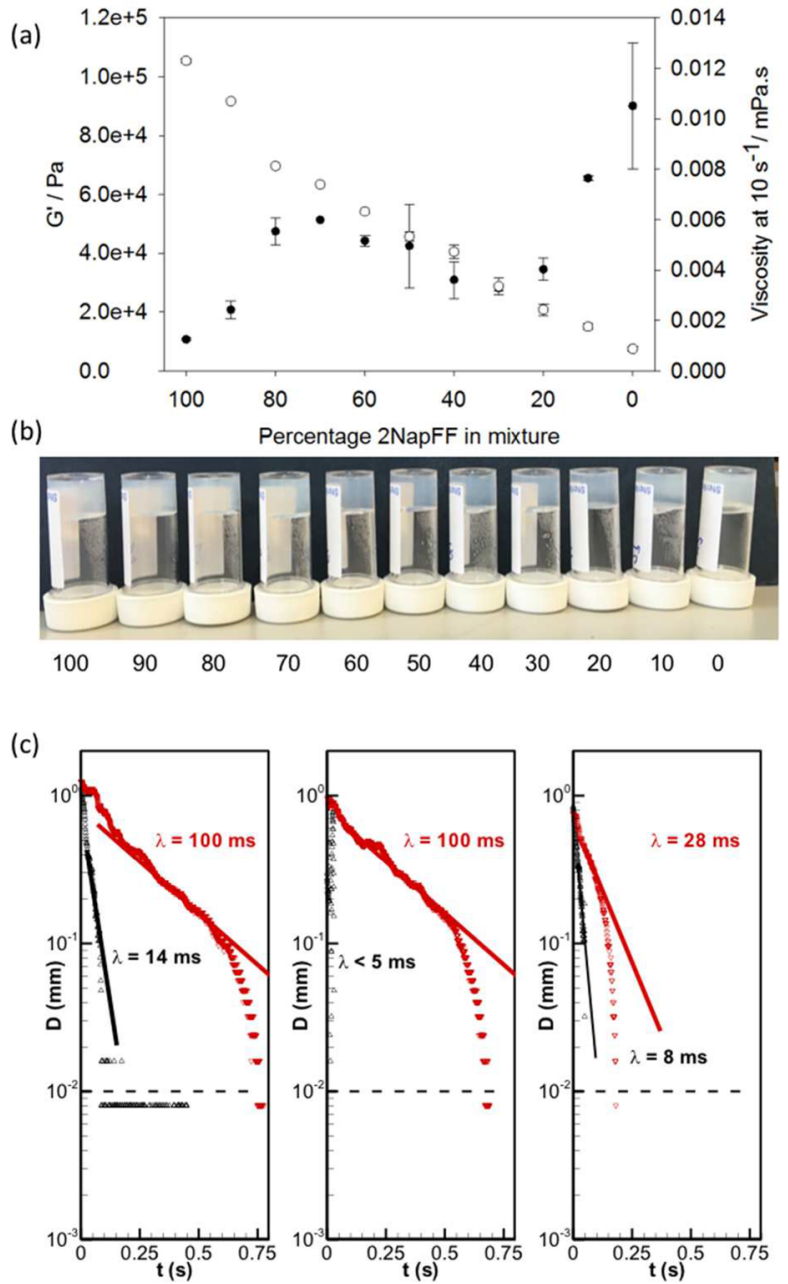

Figure 2. (a) Plot of viscosity of the solutions at high $\mathrm{pH}$ at different ratios of $2 \mathrm{NapFF}$ to $2 \mathrm{NapVG}$ (open symbols, right axis) and the storage modulus of the gels formed from these solutions at low $\mathrm{pH}$ (full symbols, left axis). (b) Photographs of the gels formed at the different ratios; the number under each vial represents the percentage of $2 \mathrm{NapFF}$ in the mixture. (c) Diameter-time data from CaBER experiments including exponential fits to obtain estimates of relaxation time $\lambda$; from left to right, data are shown for a sample at $100 \%$ $2 \mathrm{NapFF}, 70 \% 2 \mathrm{NapFF}$, and $30 \% 2 \mathrm{NapFF}$. The black data are for fresh samples, with the fit shown as a black line. The red data are for samples that have been sheared through a pipet tip, with the red line being the fit to the data. The horizontal dashed line highlights the resolution of the laser micrometer.

simply being diluted on addition of the 2NapVG. A complication here is shear history. Samples that had been previously sheared and allowed to stand before further use showed significant increases in viscosity and also exhibited a marked "stringiness" consistent with an increased extensional viscosity (see Figure S1, Supporting Information). Hence, solutions for which the viscosity was measured became more viscous with time. A number of studies ruled out that this effect was due to time and the shear applied by the rheometer for the viscosity measurements (up to $10^{2} \mathrm{~s}^{-1}$, as well as measurements at constant shear rate over extended periods of time). This increase in viscosity seems to arise from the very high shear rates applied when the samples are unloaded from the rheometer using a pipet $\left(\sim 10^{3}-10^{6} \mathrm{~s}^{-1}\right)$. To quantify the effects of shear history on the extensional viscosity of the solutions, experiments where performed using a capillary 

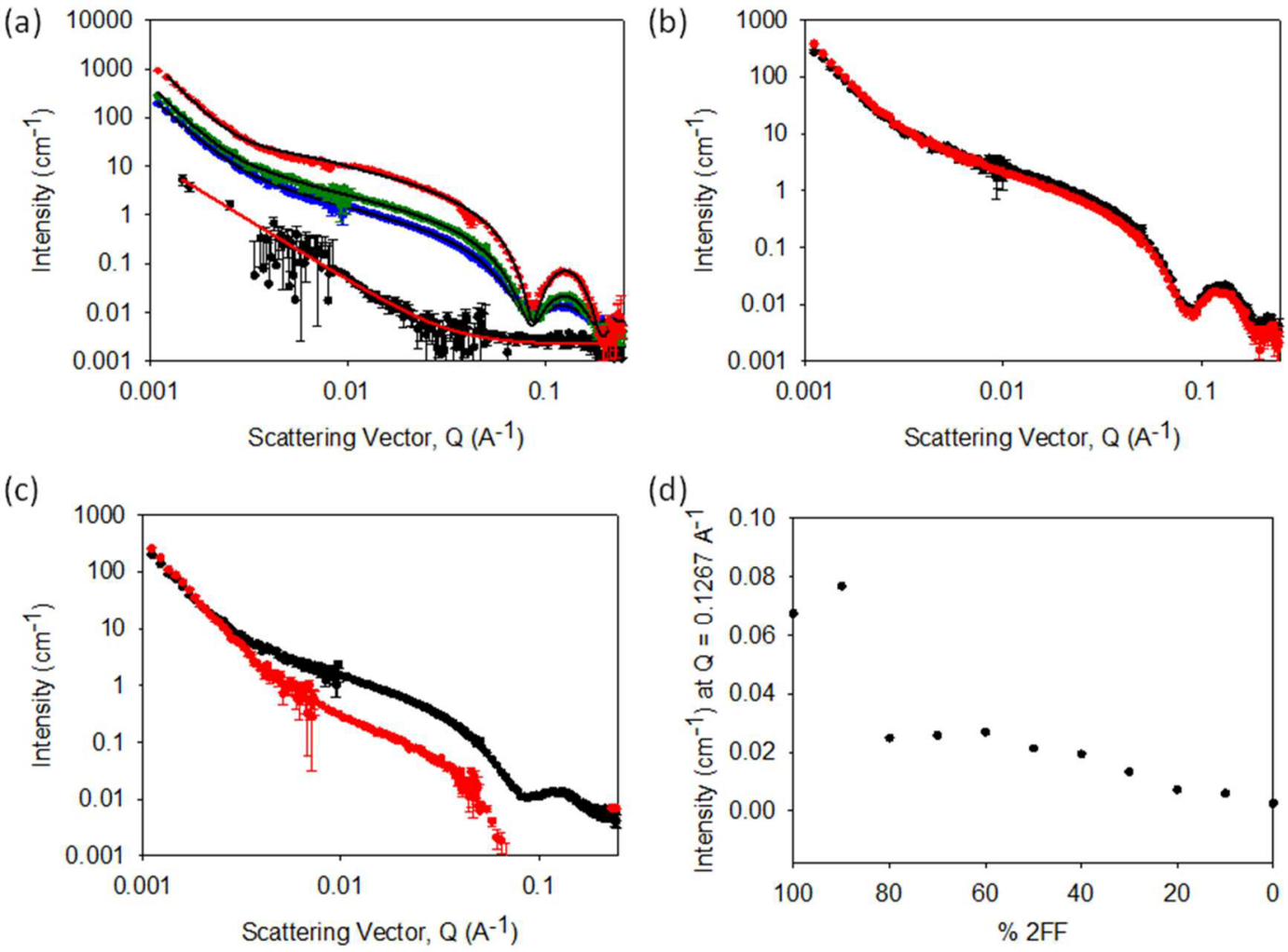

(d)

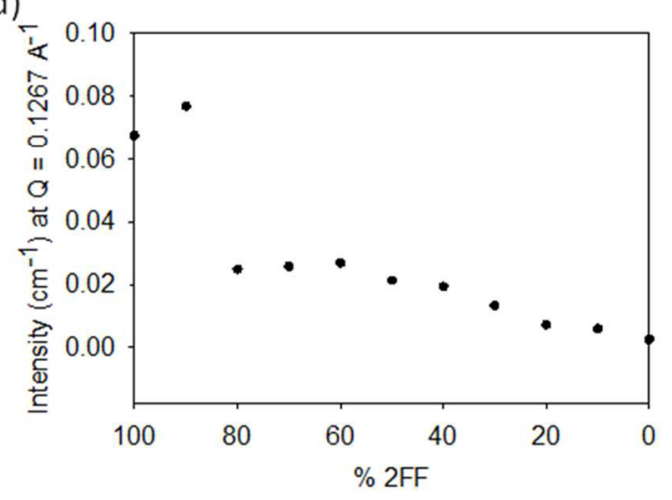

Figure 3. (a) SANS profiles for solutions at $100 \% 2 \mathrm{NapFF}$ (red), $70 \% 2 \mathrm{NapFF}$ (green), $50 \% 2 \mathrm{NapFF}$ (blue), and $0 \% 2 \mathrm{NapFF}$ (black). The fits to a hollow cylinder model combined with a power law are shown as black lines, and for the $0 \% 2 \mathrm{NapFF}$ only, the fit to a power law alone is shown as a red line. (b) Overlay of the SANS profiles for a solution of $2 \mathrm{NapFF}$ diluted 1:1 with 2NapVG (black data) or 1:1 with $\mathrm{D}_{2} \mathrm{O}$ (red data). (c) Overlay of the SANS profiles for a solution of $2 \mathrm{NapFF}$ diluted 3:7 with 2NapVG (black data) or 3:7 with $\mathrm{D}_{2} \mathrm{O}$ (red data). (d) Plot of scattering intensity at $Q$ $=0.1267 \AA^{-1}$ for solutions containing different ratios of $2 \mathrm{NapFF}$ and $2 \mathrm{NapVG}$. For all of these data, the solutions were prepared in $\mathrm{D}_{2} \mathrm{O}$, with a pD of $11.4 \pm 0.2$

breakup extensional rheometer ("CaBER") ${ }^{50}$ supplied by Haake Thermo Scientific. The diameter of the filament $(D)$ is observed as a function of time $(t)$ using the equipment's laser micrometer (resolution $\sim 10 \mu \mathrm{m})$. Although the filament diameter data can be postprocessed into an (apparent) extensional viscosity, the standard method to quantify extensional effects ${ }^{50,57}$ is via an exponential fit to the filament diameter as a function of time in the elastocapillary regime to determine a characteristic relaxation time, $\lambda$ (more correctly a characteristic time for extensional stress growth). Representative plots are shown in Figure 2c, where the effect of shear history can be seen to dramatically increase this characteristic time $\lambda$. Because of this interesting behavior, all of the following data were collected for fresh samples that had not been exposed to any additional shear history beyond that needed to freshly prepare the samples. Additionally, the uncertainties calculated for the viscosity data shown in Figure 2 were calculated from multiple fresh samples.

Solutions containing different ratios of $2 \mathrm{NapFF}$ and $2 \mathrm{NapVG}$ were then gelled. To do this, we used GdL, which hydrolyses slowly and reproducibly to gluconic acid. ${ }^{45}$ For all ratios, we used a fixed amount of GdL $(10 \mathrm{mg} / \mathrm{mL})$. With this amount of GdL, all of the ratios formed self-supporting hydrogels overnight (Figure $2 \mathrm{~b}$ ) with the $\mathrm{pH}$ of all the gels at this point being $3.7 \pm 0.1$. Interestingly, despite the near linear trend at high $\mathrm{pH}$ of a decreasing viscosity with increasing content of $2 \mathrm{NapVG}$, the storage modulus $\left(G^{\prime}\right)$ for the final gels is very nonlinear (Figure $2 \mathrm{a}$ ). Tan $\delta\left(G^{\prime \prime} / G^{\prime}\right)$ was between 0.17 and 0.20 for all gels from $100 \%$ to $20 \% 2 \mathrm{NapFF}$, rising to 0.24 at $10 \% 2 \mathrm{NapFF}$ and 0.31 for the $0 \% 2 \mathrm{NapFF}$ gel. Strain sweeps are shown in Figures S2 and S3.

The small-angle neutron scattering (SANS) data for the gels can be best fit to a combination of a flexible elliptical cylinder, in combination with an absolute power law to fit the low $Q$ region; the low $Q$ region is sensitive to the fractal scattering from the network structure (Figures S4 and S5). Fits to the cylinder or flexible cylinder models were significantly less good than the elliptical model. To fit the data, the Kuhn length was fixed to a number of values, and the fit was optimized based on the residuals. The best fit for the $100 \% 2 \mathrm{NapFF}$ gel was found with a radius of $3.55 \pm 0.05 \mathrm{~nm}$, an axis ratio of $2.58 \pm 0.04$, a Kuhn length of $20.50 \pm 1.03 \mathrm{~nm}$, and a length of $83.27 \pm 4.24$ $\mathrm{nm}$. A power law of $2.58 \pm 0.04$ was also needed. On dilution of the $2 \mathrm{NapFF}$ with $2 \mathrm{NapVG}$, the same model could be used successfully across the series of gels at low $\mathrm{pH}$, with only minor changes in all parameters. This included the gel for the $2 \mathrm{NapVG}$ alone (i.e., $0 \% 2 \mathrm{NapFF}$ ), which was found to best fit to the same model, with a radius of $4.27 \pm 0.11 \mathrm{~nm}$, an axis ratio of $2.57 \pm 0.21$, a Kuhn length of $29.19 \pm 7.34 \mathrm{~nm}$, and a length of $159.43 \pm 2.18 \mathrm{~nm}$. A power-law exponent of $2.21 \pm$ 0.03 was also needed. Hence, the SANS data imply that all networks are very similar. SEM images of the dried gels also show similar networks in all cases (Figure S6). There is a gradual increase in fiber diameter as the percentage of $2 \mathrm{NapVG}$ is increased in the mixture, with the average diameters being $22.5 \mathrm{~nm}$ for $100 \% 2 \mathrm{NapFF}, 23.5 \mathrm{~nm}$ for $70 \% 2 \mathrm{NapFF}, 26.6 \mathrm{~nm}$ for $50 \% 2 \mathrm{NapFF}, 39.2 \mathrm{~nm}$ for $30 \% 2 \mathrm{NapFF}$, and $40.0 \mathrm{~nm}$ for $0 \% 2 \mathrm{NapFF}$ (Figure S7). These values are all higher than the 
(a)

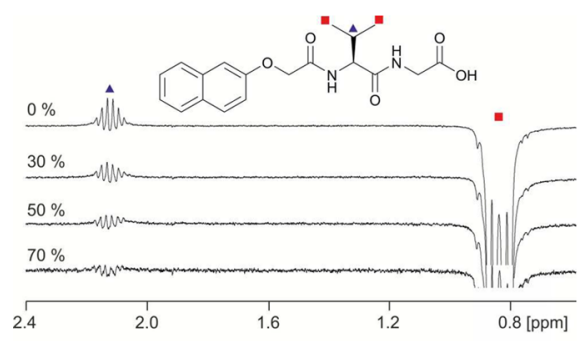

(b)
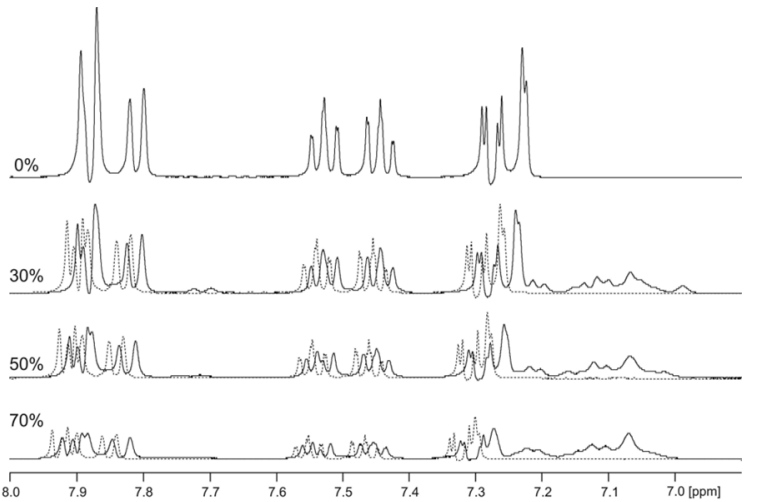

Figure 4. (a) ${ }^{1} \mathrm{H}$ NOE difference spectra of $2 \mathrm{NapVG}$ acquired at different percentages of $2 \mathrm{NapFF}$. The methyl protons (square) were selectively excited and the NOE to the $\mathrm{CH}$ protons (triangle) monitored. The spectra have been scaled according to the amount of $2 \mathrm{NapVG}$ in the samples. (b) Partial ${ }^{1} \mathrm{H}$ NMR spectra of $2 \mathrm{NapVG}$ at the proportion of $2 \mathrm{NapFF}$ indicated. The total concentration of LMWG was $10 \mathrm{mg} / \mathrm{mL}$ in all cases. Spectra recorded in the absence of $2 \mathrm{NapFF}$, but at the same concentration of $2 \mathrm{NapVG}$, are shown as dashed lines. A clear upfield shift of the aromatic protons of the $2 \mathrm{NapVG}$ is apparent when $2 \mathrm{NapFF}$ is included.

diameters measured by the SANS, which implies either that the structures imaged by SEM are aggregates of primary structures detected by SANS or that there are significant drying artifacts. There is no apparent bimodal distribution of fibers, as has been observed in some cases for self-sorting, ${ }^{11,35}$ implying that pure self-sorting is not occurring here. Since the diameters for the $30 \% 2 \mathrm{NapFF}$ and the $0 \% 2 \mathrm{NapFF}$ are very similar even though the gels have significantly different rheological properties at these two compositions, we conclude that the differences in rheological data seen in Figure 2 cannot be explained simply in terms of different types of fibers forming the networks.

To explain the nonlinear rheology at low $\mathrm{pH}$ arising from solutions with approximately linear trends in viscosity, we examined the solutions at high $\mathrm{pH}$ in more detail. The increase in extensional viscosity on shearing even at very low concentrations of $2 \mathrm{NapFF}$ in the mixture (see above) implies that the $2 \mathrm{NapVG}$ is involved in the self-assembled structures, since it is difficult to imagine how such high viscosities can be achieved at the low concentrations of $2 \mathrm{NapFF}$. To probe this, we turned again to SANS. We have previously shown that the SANS data for solutions of $2 \mathrm{NapFF}$ at high $\mathrm{pH}$ can be fitted to a hollow cylinder model, again combined with a power law component to fit the low $Q$ region. ${ }^{38}$ The scattering data from all of the solutions of $2 \mathrm{NapFF}$ and $2 \mathrm{NapVG}$ at high $\mathrm{pH}$ were found to fit well to this model, apart from the data for pure 2NapVG (Figure 3a and Figures S8 and S9). The pure $2 \mathrm{NapVG}$ exhibited very low scattering at high $\mathrm{pH}$, and the data could be fitted well to a power law alone. From the fits to the data from the other solutions, it can be seen that the internal and external radii of the hollow cylinder do not vary much across the dilution series. For pure $2 \mathrm{NapFF}$, the core radius determined from the fit is $1.50 \pm 0.11 \mathrm{~nm}$ and the external radius is $4.06 \pm 0.10 \mathrm{~nm}$, in close agreement with our previous data. ${ }^{38}$ At $70 \%, 50 \%$, and $30 \% 2 \mathrm{NapFF}$, the core radii are 1.66 $\pm 0.18,1.58 \pm 0.22$, and $1.57 \pm 0.3 \mathrm{~nm}$, respectively, and the external radii $3.79 \pm 0.13,3.86 \pm 0.15$, and $3.90 \pm 0.22 \mathrm{~nm}$, respectively. Further, from the scattering intensities, it is clear that there is not a linear decrease in intensity across the dilution series (Figure 3d).

This again implies that the two LMWG are not completely self-sorted at high $\mathrm{pH}$, and potentially the structures formed are directed by the $2 \mathrm{NapFF}$ in a "sergeants and soldiers" manner. ${ }^{58,59}$ Further evidence for this comes from a direct comparison between solutions of $2 \mathrm{NapFF}$ diluted with solutions of $2 \mathrm{NapVG}$ and those diluted with $\mathrm{D}_{2} \mathrm{O}$ (for SANS experiments, it is necessary to replace the $\mathrm{H}_{2} \mathrm{O}$ solvent with $\mathrm{D}_{2} \mathrm{O}$ ). Here, at high ratios of the $2 \mathrm{NapFF}$, the scattering is very similar in intensity between the two methods of dilution (Figure $3 \mathrm{~b}$ ). However, for the low ratios of $2 \mathrm{NapFF}$, there are significant differences between the dilution methods (Figure $3 \mathrm{c})$. On diluting $2 \mathrm{NapFF}$ with $\mathrm{D}_{2} \mathrm{O}$, the scattering is significantly decreased, especially at high $Q$. This is similar to what we showed previously for diluted solutions of $2 \mathrm{NapFF}{ }^{38}$ However, on dilution with the $2 \mathrm{NapVG}$, the scattering was significantly higher as compared to the dilution with $\mathrm{D}_{2} \mathrm{O}$ and still showed the characteristic scattering of the hollow cylinders (Figure 3c). All of these data strongly imply that the solutions are not self-sorted at high $\mathrm{pH}$, but rather the assembly is directed by even relatively low amounts of the $2 \mathrm{NapFF}$.

Finally, further evidence for interaction at high $\mathrm{pH}$ comes from NMR spectroscopy (Figure 4). In the absence of $2 \mathrm{NapFF}$, selective excitation of the methyl protons of the valine residue enhances the signal of the neighboring $\mathrm{CH}$ protons (Figure 4a). Such a positive NOE is indicative of fast molecular motions, indicating minimal aggregation of the gelators. As the proportion of $2 \mathrm{NapFF}$ is raised, the size of the enhancement diminishes and becomes slightly negative, indicating a significant decrease in the molecular mobility of the $2 \mathrm{NapVG}$ due to interaction with the $2 \mathrm{NapFF} .^{60}$ Furthermore, the chemical shifts of the aromatic protons of $2 \mathrm{NapVG}$ are shifted upfield by the presence of the $2 \mathrm{NapFF}$, consistent with an increased level of aggregation (Figure $4 \mathrm{~b}$ ). ${ }^{61}$

We interpret these data as there being a significant proportion of the $2 \mathrm{NapVG}$ that is exchanging in solution with the assembled structures of the $2 \mathrm{NapFF}$. Since the $2 \mathrm{NapVG}$ is detectable by NMR (and indeed the concentration detected scales with the expected amount in the mixture (Figure S10)), the 2NapVG must be exchanging with the assembled structure at a faster rate than the $2 \mathrm{NapFF}$ molecules. Hence, these data suggest that both molecules are present in the same aggregates at high $\mathrm{pH}$. The aromatic ${ }^{1} \mathrm{H}$ chemical shifts of the $2 \mathrm{NapVG}$ are moved upfield in the presence of $2 \mathrm{NapFF}$ (Figure $4 \mathrm{~b}$ ). The shifts of the amino acid side chains are much less affected. On the basis of the work of Orfi et al., ${ }^{62}$ we therefore infer that the hydrophobic naphthalene group penetrates the structures formed by the $2 \mathrm{NapFF}$ while the 
negatively charged peptide motif of the $2 \mathrm{NapVG}$ remains in contact with the external solution. The $2 \mathrm{NapVG}$ is thus behaving as a surfactant. However, on drying it is clear that exchange must be occurring, as the dried solutions show both wormlike micelles (expected from the $2 \mathrm{NapFF}$ ) and ill-defined aggregates (expected from $2 \mathrm{NapVG}$ on the basis of other work). Example SEM images are shown in Figure S11.

Having determined that there is mixing at high $\mathrm{pH}$, the next question arising is whether self-sorting occurs when the $\mathrm{pH}$ is decreased. It is conceptually possible that the aggregates at high $\mathrm{pH}$ might template assembly such that a mixed fiber system is formed. Alternatively, the two components could reorder such that self-sorted fibers are formed (Figure 1). For previous mixtures of related LMWG, we have exploited the hydrolysis of GdL to gluconic acid to provide a controlled, reproducible slow change in $\mathrm{pH}$ to allow a combination of $\mathrm{pH}$ measurements, NMR integration, and rheological data to be collected over time to probe for self-sorting on gelation. ${ }^{34,36,37}$ Others have now also used this approach. ${ }^{17,63-65}$

For the systems here, we have followed the gelation using ${ }^{1} \mathrm{H}$ NMR spectroscopy. Here, we measure the sample over time; as the gelators assemble, the signals attenuate and the signal intensity decreases. Hence, it is possible to judge whether selfsorting has occurred from whether one gelator disappears from the NMR spectra at a different time to the second. In some cases, it is possible to observe two distinct plateaus in the $\mathrm{pH}$ data if the $\mathrm{p} K_{\mathrm{a}}$ of the two gelators is sufficiently different. ${ }^{35,36}$ In the current work, we have also exploited a method developed in house to measure the $\mathrm{pH}$ in situ in the NMR tube. ${ }^{53}$

Here, for the mixtures, a difficulty is that the signal intensity for the $2 \mathrm{NapFF}$ is low even at high $\mathrm{pH}$, when less than $20 \%$ is detectable by NMR at $10 \mathrm{mg} / \mathrm{mL}$ concentration. ${ }^{38}$ We have described this before; ${ }^{38}$ we interpret this as the $2 \mathrm{NapFF}$ forming persistent wormlike micelles that mean that the gelator is spending most of the time at high $\mathrm{pH}$ as part of a selfassembled structure. Strong saturation-transfer-difference (STD) effects are apparent to the NMR-visible $2 \mathrm{NapFF}$ as it interacts/exchanges with these structures (Figure S12). As such, it is not possible to monitor effectively the assembly of the $2 \mathrm{NapFF}$ by NMR. The $2 \mathrm{NapVG}$, however, is detectable across the concentration series, which implies that at high $\mathrm{pH}$ the gelators are essentially unassembled (Figure S10). No significant STD effects are observed to the $2 \mathrm{NapVG}$ at high $\mathrm{pH}$, indicating a minimal degree of aggregation compared to the $2 \mathrm{NapFF}$.

For 2NapVG alone, the $\mathrm{pH}$ and NMR data are as expected (Figure $5 \mathrm{~d}$ ). The $\mathrm{pH}$ drops to a plateau at the expected $\mathrm{p} K_{\mathrm{a}}$ of the gelator (5.0). The shape of the $\mathrm{pH}$ data is similar to that shown elsewhere for samples where the $\mathrm{pH}$ is changed using $\mathrm{GdL}^{42,66}$ the $\mathrm{pH}$ drops to a value slightly below the apparent $\mathrm{p} K_{\mathrm{a}}$, before increasing to the $\mathrm{p} K_{\mathrm{a}}$ value, and then buffers before decreasing again. At this $\mathrm{pH}$ drop and increase, the signal intensity of the $2 \mathrm{NapVG}$ starts to drop and completely attenuates over several hours. For $2 \mathrm{NapFF}$ alone, the $\mathrm{pH}$ falls to around the expected $\mathrm{p} K_{\mathrm{a}}$ of the compound and then exhibits a smooth decrease. There is no rise in the $\mathrm{pH}$ followed by a plateau as the structures are already assembled (Figure S13). No $2 \mathrm{NapFF}$ is detectable by NMR following the addition of GdL.

For the mixtures, the situation is more complicated than would be expected from our previous reports on self-sorted two-component gelators. ${ }^{34,37}$ This in itself implies that the situation is more complicated than simple self-sorting. In the
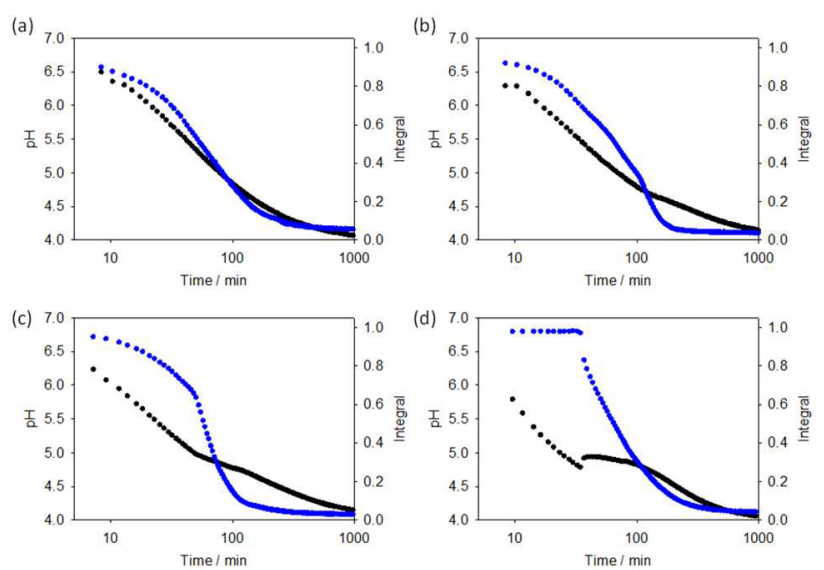

Figure 5. Plots of change in $\mathrm{pH}$ (black data) and normalized intensity of the NMR integrals of the valine peaks of $2 \mathrm{NapVG}$ (blue data) with time after addition of GdL to solutions of (a) $70 \%$ 2NapFF, (b) $50 \%$ $2 \mathrm{NapFF}$, (c) 30\% 2NapFF, and (d) 0\% 2NapFF.

absence of $2 \mathrm{NapFF}$, the assembly of $2 \mathrm{NapVG}$ occurs at a progressively lower $\mathrm{pH}$ as the concentration of gelator is decreased (Figure S14). As discussed elsewhere, the apparent $\mathrm{p} K_{\mathrm{a}}$ of a gelator is determined by its degree of aggregation and thus its concentration. ${ }^{17,48,54}$ By analysis of the $\mathrm{pH}$ profiles and $2 \mathrm{NapVG}$ signal intensities, it is readily apparent that the assembly of the $2 \mathrm{NapVG}$ is strongly influenced by the presence of the $2 \mathrm{NapFF}$. At $30 \% 2 \mathrm{NapFF}$, the $\mathrm{pH}$ drop does not have a distinct increase at the apparent $\mathrm{p} K_{\mathrm{a}}$ of the $2 \mathrm{NapVG}$ (4.7 at 7 $\mathrm{mg} / \mathrm{mL} 2 \mathrm{NapVG}$ ). However, there is an inflection point at this $\mathrm{pH}$ value. The decrease in the signal intensity of the $2 \mathrm{NapVG}$ occurs significantly before the $\mathrm{pH}$ reaches the expected $\mathrm{p} K_{a}$ although the rate of the decrease in signal increases after this $\mathrm{pH}$. At $50 \% 2 \mathrm{NapFF}$, the $\mathrm{pH}$ decrease has no obvious inflection points at the apparent $\mathrm{p} K_{\mathrm{a}}$ of 4.5 . The intensity of the $2 \mathrm{NapVG}$ integral again decreases at a $\mathrm{pH}$ far higher than the apparent $\mathrm{p} K_{\mathrm{a}}$ of the $2 \mathrm{NapVG}$. Only approximately $20 \%$ of the $2 \mathrm{NapVG}$ is detectable by NMR at its $\mathrm{p} K_{\mathrm{a}}$. At $70 \% 2 \mathrm{NapFF}$, the $\mathrm{pH}$ data again show no inflection. In the absence of $2 \mathrm{NapFF}, 2 \mathrm{NapVG}$ at $3 \mathrm{mg} / \mathrm{mL}$ concentration remains unassembled, even when the $\mathrm{pH}$ has fallen to 4.2 (Figure S13).

These data strongly suggest a coassembly of the two gelators, at least at certain relative concentrations. At 50\% and 30\% $2 \mathrm{NapFF}$, there is a fraction of the $2 \mathrm{NapVG}$ that seems to behave as expected in terms of the rate of signal decrease with $\mathrm{pH}$. However, a significant fraction of the $2 \mathrm{NapVG}$ signal intensity decreases before the expected $\mathrm{p} K_{a}$, implying that it is coassembling with the $2 \mathrm{NapFF}$.

Hence, we interpret the nonlinear rheological data as being due to a spectrum of behavior across the series of mixtures. The $2 \mathrm{NapVG}$ is exchanging in solution with aggregates determined by the $2 \mathrm{NapFF}$ in a "sergeants and soldiers" manner. Because of the fast exchange, however, only a proportion of the $2 \mathrm{NapVG}$ is incorporated in the gel fibers formed by $2 \mathrm{NapFF}$ as the $\mathrm{pH}$ drops. The remainder of the $2 \mathrm{NapVG}$ will presumably be able to act as a surfactant as the gelling is occurring, potentially modifying the fiber network that is growing (again, we have previously shown that this type of LMWG can act as a surfactant $\left.{ }^{38,41}\right)$. We stress here that this does not have to be a modification of the fibers themselves; rather, it could be that the $2 \mathrm{NapVG}$ modifies the tendency of the $2 \mathrm{NapFF}$ fibers to entangle and cross-link. This would then affect the rheological data of the gel, without requiring a significant change in the 
morphology of the fibers. After the $2 \mathrm{NapFF}$ has gelled, the remainder of the $2 \mathrm{NapVG}$ will form fibers, contributing to the rheological data. Schematically, we illustrate this in Figure 6.

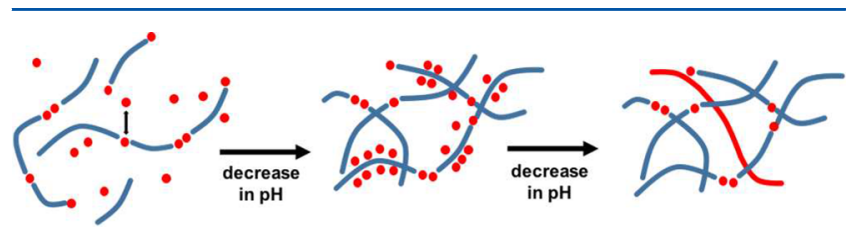

Figure 6. Cartoon showing the assembly of a mixture of $2 \mathrm{NapFF}$ (blue) and $2 \mathrm{NapVG}$ (red). Partial coassembly occurs as the $\mathrm{pH}$ drops, but the fast exchange of the $2 \mathrm{NapVG}$ from the micellar aggregates results in a fraction of the $2 \mathrm{NapVG}$ not being incorporated; this assembles alone as the $\mathrm{pH}$ drops further.

Hence, the gel's mechanical properties will be very sensitive to the absolute ratio of the $2 \mathrm{NapFF}$ and $2 \mathrm{NapVG}$, as well as to the kinetics of gelation, which will presumably determine how much $2 \mathrm{NapVG}$ is incorporated into the fibers that are being directed by the $2 \mathrm{NapFF}$.

\section{CONCLUSIONS}

Two-component supramolecular gels are extremely complex. There is ever increasing interest in these multicomponent systems, but there are few studies showing how the assembly is affected by the relative ratios of the components. It is clear from our data here that kinetics is an extremely important factor. For these $\mathrm{pH}$-triggered gelators, there are nonlinear effects in terms of the rheological data. Conceptually, the two components can intermix or remain independent at high $\mathrm{pH}$ and then coassemble or self-sort as the $\mathrm{pH}$ is decreased. Here, we have shown that the situation for a mixture of $2 \mathrm{NapFF}$ and $2 \mathrm{NapVG}$ is more complex than these simple either/or cases. At high $\mathrm{pH}$, intermixing is occurring, at least to some degree. As the $\mathrm{pH}$ is decreased, there is a partial coassembly of the two gelling components. From the NMR data, there are clearly two stages by which the $2 \mathrm{NapVG}$ assembles in the mixtures. The first stage is above the expected $\mathrm{p} K_{\mathrm{a}}$ of the $2 \mathrm{NapVG}$. The fraction that assembles above this expected $\mathrm{p} K_{\mathrm{a}}$ depends on the mixture ratio. We assign this stage to coassembly of both LMWG. At later times, the $\mathrm{pH}$ drops to the $\mathrm{p} K_{\mathrm{a}}$ of the $2 \mathrm{NapVG}$, and there is a different rate of assembly. Hence, we assign these as a coassembly stage and a stage where the $2 \mathrm{NapVG}$ assembles alone. When assembling alone, it is possible that the $2 \mathrm{NapVG}$ is forming an independent network, or it could be that it is assembling on the preformed mixed network. As a result of this complicated situation, the rheological data for the gels formed at different ratios of the two gelators are nonlinear, despite the fibers forming the networks being similar in all cases.

We have shown previously for this family of gelator that selfsorting can be controlled by the differences in $\mathrm{p} K_{\mathrm{a}}$ for a number of examples. ${ }^{34,36,37}$ However, we have previously found one example where coassembly occurred despite a difference in $\mathrm{p} K_{\mathrm{a}}$ of around one unit; this example involved two structurally similar gelators, which only differed by the terminal amino acid. $^{34}$ As such, it is clear that a difference in $p K_{a}$ is not a sufficient driving force for self-sorting. While the current two gelators are not as structurally related as our coassembling example, we also note that the system presented here involves one LMWG that forms persistent wormlike micelles. It may be that the type of micelle formed at high $\mathrm{pH}$ is important as our previous examples of effective self-sorting have been for systems where both gelators form nonpersistent micelles at high $\mathrm{pH}$. We note again that there are very limited data on mixed gelators and self-sorting or mixing, and in some cases, the type of assembly seems to be assumed as opposed to proven. ${ }^{9}$ In this paper, we have shown that simple assumptions as to whether or not coassembly or self-sorting are occurring in a system may not always hold and that simply mixing at one specific ratio is insufficient to truly understand these systems.

\section{ASSOCIATED CONTENT}

\section{S Supporting Information}

The Supporting Information is available free of charge on the ACS Publications website at DOI: 10.1021/acs.langmuir.7b00326.

Further rheological data, NMR data, SANS data and fits, SEM images, and $\mathrm{pH}$ titrations (PDF)

\section{AUTHOR INFORMATION}

\section{Corresponding Author}

*E-mail dave.adams@glasgow.ac.uk (D.J.A.).

ORCID $\odot$

Dave J. Adams: 0000-0002-3176-1350

Notes

The authors declare no competing financial interest.

\section{ACKNOWLEDGMENTS}

D.A. thanks the EPSRC for a Fellowship (EP/L021978/1), which also funded E.D. The experiment at the Institut Laue Langevin was allocated beam time under experiment number 911-1802 (DOI: 10.5291/ILL-DATA.9-11-1802). This work benefitted from the SasView software, originally developed by the DANSE project under NSF award DMR-0520547. The NMR spectrometers used for this work were funded by the EPSRC (EP/K039687/1 and EP/C005643/1).

\section{REFERENCES}

(1) Hirst, A. R.; Escuder, B.; Miravet, J. F.; Smith, D. K. High-Tech Applications of Self-Assembling Supramolecular Nanostructured GelPhase Materials: From Regenerative Medicine to Electronic Devices. Angew. Chem., Int. Ed. 2008, 47, 8002-8018.

(2) Weiss, R. G. The Past, Present, and Future of Molecular Gels. What Is the Status of the Field, and Where Is It Going? J. Am. Chem. Soc. 2014, 136, 7519-7530.

(3) Skilling, K. J.; Citossi, F.; Bradshaw, T. D.; Ashford, M.; Kellam, B.; Marlow, M. Insights into low molecular mass organic gelators: a focus on drug delivery and tissue engineering applications. Soft Matter 2014, 10, 237-256.

(4) Du, X.; Zhou, J.; Shi, J.; Xu, B. Supramolecular Hydrogelators and Hydrogels: From Soft Matter to Molecular Biomaterials. Chem. Rev. 2015, 115, 13165-13307.

(5) Babu, S. S.; Praveen, V. K.; Ajayaghosh, A. Functional $\pi$-Gelators and Their Applications. Chem. Rev. 2014, 114, 1973-2129.

(6) de Loos, M.; Feringa, B. L.; van Esch, J. H. Design and Application of Self-Assembled Low Molecular Weight Hydrogels. Eur. J. Org. Chem. 2005, 2005, 3615-3631.

(7) Worthington, P.; Pochan, D. J.; Langhans, S. A. Peptide Hydrogels - Versatile Matrices for 3D Cell Culture in Cancer Medicine. Front. Oncol. 2015, 5, 92.

(8) Buerkle, L. E.; Rowan, S. J. Supramolecular gels formed from multi-component low molecular weight species. Chem. Soc. Rev. 2012, 41, 6089-6102.

(9) Raeburn, J.; Adams, D. J. Multicomponent low molecular weight gelators. Chem. Commun. 2015, 51, 5170-5180. 
(10) Smith, M. M.; Smith, D. K. Self-sorting multi-gelator gels-mixing and ageing effects in thermally addressable supramolecular soft nanomaterials. Soft Matter 2011, 7, 4856-4860.

(11) Moffat, J. R; Smith, D. K. Controlled self-sorting in the assembly of 'multi-gelator' gels. Chem. Commun. 2009, 316-318.

(12) Alakpa, E. V.; Jayawarna, V.; Lampel, A.; Burgess; Karl, V.; West; Christopher, C.; Bakker; Sanne, C. J.; Roy, S.; Javid, N.; Fleming, S.; Lamprou; Dimitris, A.; Yang, J.; Miller, A.; Urquhart; Andrew, J.; Frederix; Pim, W. J. M.; Hunt; Neil, T.; Péault, B.; Ulijn; Rein, V.; Dalby; Matthew, J. Tunable Supramolecular Hydrogels for Selection of Lineage-Guiding Metabolites in Stem Cell Cultures. Chem. 2016, 1, 298-319.

(13) Liyanage, W.; Nilsson, B. L. Substituent Effects on the SelfAssembly/Coassembly and Hydrogelation of Phenylalanine Derivatives. Langmuir 2016, 32, 787-799.

(14) Felip-León, C.; Díaz-Oltra, S.; Galindo, F.; Miravet, J. F. Chameleonic, Light Harvesting Photonic Gels Based on Orthogonal Molecular Fibrillization. Chem. Mater. 2016, 28, 7964-7972.

(15) Fichman, G.; Guterman, T.; Adler-Abramovich, L.; Gazit, E. Synergetic functional properties of two-component single amino acidbased hydrogels. CrystEngComm 2015, 17, 8105-8112.

(16) Edwards, W.; Smith, D. K. Enantioselective Component Selection in Multicomponent Supramolecular Gels. J. Am. Chem. Soc. 2014, 136, 1116-1124.

(17) Tena-Solsona, M.; Escuder, B.; Miravet, J. F.; Casttelleto, V.; Hamley, I. W.; Dehsorkhi, A. Thermodynamic and Kinetic Study of the Fibrillization of a Family of Tetrapeptides and Its Application to Self-Sorting. What Takes So Long? Chem. Mater. 2015, 27, 33583365 .

(18) Hsu, S.-M.; Wu, F.-Y.; Lai, T.-S.; Lin, Y.-C.; Lin, H.-C. Selfassembly and hydrogelation from multicomponent coassembly of pentafluorobenzyl-phenylalanine and pentafluorobenzyl-diphenylalanine. RSC Adv. 2015, 5, 22943-22946.

(19) Kölbel, M.; Menger, F. M. Molecular Recognition among Structurally Similar Components of a Self-Assembling Soft Material. Langmuir 2001, 17, 4490-4492.

(20) Elsawy, M. A.; Smith, A. M.; Hodson, N.; Squires, A.; Miller, A. F.; Saiani, A. Modification of $\beta$-Sheet Forming Peptide Hydrophobic Face: Effect on Self-Assembly and Gelation. Langmuir 2016, 32, 4917-4923.

(21) Ikeda, M.; Tanida, T.; Yoshii, T.; Kurotani, K.; Onogi, S.; Urayama, K.; Hamachi, I. Installing logic-gate responses to a variety of biological substances in supramolecular hydrogel-enzyme hybrids. Nat. Chem. 2014, 6, 511-518.

(22) Onogi, S.; Shigemitsu, H.; Yoshii, T.; Tanida, T.; Ikeda, M.; Kubota, R.; Hamachi, I. In situ real-time imaging of self-sorted supramolecular nanofibres. Nat. Chem. 2016, 8, 743-752.

(23) Görl, D.; Zhang, X.; Stepanenko, V.; Würthner, F. Supramolecular block copolymers by kinetically controlled co-self-assembly of planar and core-twisted perylene bisimides. Nat. Commun. 2015, 6, 7009.

(24) Rohner, S. S.; Ruiz-Olles, J.; Smith, D. K. Speed versus stability structure-activity effects on the assembly of two-component gels. RSC Adv. 2015, 5, 27190-27196.

(25) Singh, N.; Maity, C.; Zhang, K.; Angulo-Pachón, C. A.; van Esch, J. H.; Eelkema, R; Escuder, B. Synthesis of a Double-Network Supramolecular Hydrogel by Having One Network Catalyse the Formation of the Second. Chem. - Eur. J. 2017, 23, 2018.

(26) Singh, N.; Zhang, K.; Angulo-Pachon, C. A.; Mendes, E.; van Esch, J. H.; Escuder, B. Tandem reactions in self-sorted catalytic molecular hydrogels. Chem. Sci. 2016, 7, 5568-5572.

(27) Horgan, C. C.; Rodriguez, A. L.; Li, R.; Bruggeman, K. F.; Stupka, N.; Raynes, J. K.; Day, L.; White, J. W.; Williams, R. J.; Nisbet, D. R. Characterisation of minimalist co-assembled fluorenylmethyloxycarbonyl self-assembling peptide systems for presentation of multiple bioactive peptides. Acta Biomater. 2016, 38, 11-22.

(28) Sandeep, A.; Praveen, V. K.; Kartha, K. K.; Karunakaran, V.; Ajayaghosh, A. Supercoiled fibres of self-sorted donor-acceptor stacks: a turn-off/turn-on platform for sensing volatile aromatic compounds. Chem. Sci. 2016, 7, 4460-4467.

(29) Ardona, H. A. M.; Tovar, J. D. Energy transfer within responsive pi-conjugated coassembled peptide-based nanostructures in aqueous environments. Chem. Sci. 2015, 6, 1474-1484.

(30) Medini, K.; West, B.; Williams, D. E.; Brimble, M. A.; Gerrard, J. A. MALDI-imaging enables direct observation of kinetic and thermodynamic products of mixed peptide fiber assembly. Chem. Commun. 2017, 53, 1715-1718.

(31) Fan, K.; Kong, H.; Wang, X.; Yang, X.; Song, J. Tunable selfassembly of two-component gels from novel sorbitol-appended compounds. RSC Adv. 2016, 6, 80934-80938.

(32) Safont-Sempere, M. M.; Fernández, G.; Würthner, F. SelfSorting Phenomena in Complex Supramolecular Systems. Chem. Rev. 2011, 111, 5784-5814.

(33) Li, D.; Shi, Y.; Wang, L. Mechanical Reinforcement of Molecular Hydrogel by Co-assembly of Short Peptide-based Gelators with Different Aromatic Capping Groups. Chin. J. Chem. 2014, 32, 123127.

(34) Colquhoun, C.; Draper, E. R.; Eden, E. G. B.; Cattoz, B. N.; Morris, K. L.; Chen, L.; McDonald, T. O.; Terry, A. E.; Griffiths, P. C.; Serpell, L. C.; Adams, D. J. The effect of self-sorting and co-assembly on the mechanical properties of low molecular weight hydrogels. Nanoscale 2014, 6, 13719-13725.

(35) Draper, E. R.; Lee, J. R.; Wallace, M.; Jackel, F.; Cowan, A. J.; Adams, D. J. Self-sorted photoconductive xerogels. Chem. Sci. 2016, 7, 6499-6505.

(36) Draper, E. R.; Eden, E. G. B.; McDonald, T. O.; Adams, D. J. Spatially resolved multicomponent gels. Nat. Chem. 2015, 7, 848-852.

(37) Morris, K. L.; Chen, L.; Raeburn, J.; Sellick, O. R.; Cotanda, P.; Paul, A.; Griffiths, P. C.; King, S. M.; O’Reilly, R. K.; Serpell, L. C.; Adams, D. J. Chemically programmed self-sorting of gelator networks. Nat. Commun. 2013, 4, 1480.

(38) Cardoso, A. Z.; Mears, L. L. E.; Cattoz, B. N.; Griffiths, P. C.; Schweins, R.; Adams, D. J. Linking micellar structures to hydrogelation for salt-triggered dipeptide gelators. Soft Matter 2016, 12, 3612-3621.

(39) Chen, L.; McDonald, T. O.; Adams, D. J. Salt-induced hydrogels from functionalised-dipeptides. RSC $A d v$. 2013, 3, 8714-8720.

(40) Tang, C.; Smith, A. M.; Collins, R. F.; Ulijn, R. V.; Saiani, A. Fmoc-Diphenylalanine Self-Assembly Mechanism Induces Apparent pKa Shifts. Langmuir 2009, 25, 9447-9453.

(41) Li, T.; Kalloudis, M.; Cardoso, A. Z.; Adams, D. J.; Clegg, P. S. Drop-Casting Hydrogels at a Liquid Interface: The Case of Hydrophobic Dipeptides. Langmuir 2014, 30, 13854-13860.

(42) Chen, L.; Morris, K.; Laybourn, A.; Elias, D.; Hicks, M. R.; Rodger, A.; Serpell, L.; Adams, D. J. Self-Assembly Mechanism for a Naphthalene-Dipeptide Leading to Hydrogelation. Langmuir 2010, 26, 5232-5242.

(43) Fichman, G.; Gazit, E. Self-assembly of short peptides to form hydrogels: Design of building blocks, physical properties and technological applications. Acta Biomater. 2014, 10, 1671-1682.

(44) Yang, Z.; Liang, G.; Ma, M.; Gao, Y.; Xu, B. Conjugates of naphthalene and dipeptides produce molecular hydrogelators with high efficiency of hydrogelation and superhelical nanofibers. J. Mater. Chem. 2007, 17, 850-854.

(45) Adams, D. J.; Butler, M. F.; Frith, W. J.; Kirkland, M.; Mullen, L.; Sanderson, P. A new method for maintaining homogeneity during liquid-hydrogel transitions using low molecular weight hydrogelators. Soft Matter 2009, 5, 1856-1862.

(46) Draper, E. R.; Mears, L. L. E.; Castilla, A. M.; King, S. M.; McDonald, T. O.; Akhtar, R.; Adams, D. J. Using the hydrolysis of anhydrides to control gel properties and homogeneity in pH-triggered gelation. RSC Adv. 2015, 5, 95369-95378.

(47) Fleming, S.; Debnath, S.; Frederix, P. W. J. M.; Hunt, N. T.; Ulijn, R. V. Insights into the Coassembly of Hydrogelators and Surfactants Based on Aromatic Peptide Amphiphiles. Biomacromolecules 2014, 15, 1171-1184. 
(48) Chen, L.; Revel, S.; Morris, K.; Serpell, L. C.; Adams, D. J. Effect of Molecular Structure on the Properties of Naphthalene-Dipeptide Hydrogelators. Langmuir 2010, 26, 13466-13471.

(49) Houton, K. A.; Morris, K. L.; Chen, L.; Schmidtmann, M.; Jones, J. T. A.; Serpell, L. C.; Lloyd, G. O.; Adams, D. J. On Crystal versus Fiber Formation in Dipeptide Hydrogelator Systems. Langmuir 2012, 28, 9797-9806.

(50) Rodd, L. E.; Scott, T. P.; Cooper-White, J. J.; McKinley, G. H. Capillary Break-up Rheometry of Low-Viscosity Elastic Fluids. Appl. Rheol. 2005, 15, 12-27.

(51) http://www.sasview.org/.

(52) Liu, M.; Mao, X.-A.; Ye, C.; Huang, H.; Nicholson, J. K.; Lindon, J. C. Improved WATERGATE Pulse Sequences for Solvent Suppression in NMR Spectroscopy. J. Magn. Reson. 1998, 132, 125129.

(53) Wallace, M.; Iggo, J. A.; Adams, D. J. Probing the surface chemistry of self-assembled peptide hydrogels using solution-state NMR spectroscopy. Soft Matter 2017, DOI: 10.1039/C6SM02404A.

(54) Wallace, M.; Iggo, J. A.; Adams, D. J. Using solution state NMR spectroscopy to probe NMR invisible gelators. Soft Matter 2015, 11, 7739-7747.

(55) Krężel, A.; Bal, W. A formula for correlating $\mathrm{pKa}$ values determined in $\mathrm{D}_{2} \mathrm{O}$ and $\mathrm{H}_{2} \mathrm{O}$. J. Inorg. Biochem. 2004, 98, 161-166.

(56) Popov, K.; Ronkkomaki, H.; Lajunen, L. H. J. Guidelines for NMR Measurements for Determination of High and Low pKa Values. Pure Appl. Chem. 2006, 78, 663-675.

(57) Campo-Deaño, L.; Clasen, C. The slow retraction method (SRM) for the determination of ultra-short relaxation times in capillary breakup extensional rheometry experiments. J. Non-Newtonian Fluid Mech. 2010, 165, 1688-1699.

(58) Langeveld-Voss, B. M. W.; Waterval, R. J. M.; Janssen, R. A. J.; Meijer, E. W. Principles of "Majority Rules" and "Sergeants and Soldiers" Applied to the Aggregation of Optically Active Polythiophenes: Evidence for a Multichain Phenomenon. Macromolecules 1999, 32, 227-230.

(59) Foster, J. A.; Edkins, R. M.; Cameron, G. J.; Colgin, N.; Fucke, K.; Ridgeway, S.; Crawford, A. G.; Marder, T. B.; Beeby, A.; Cobb, S. L.; Steed, J. W. Blending Gelators to Tune Gel Structure and Probe Anion-Induced Disassembly. Chem. - Eur. J. 2014, 20, 279-291.

(60) Nebot, V. J.; Escuder, B.; Miravet, J. F.; Smets, J.; FernándezPrieto, S. Interplay of Molecular Hydrogelators and SDS Affords Responsive Soft Matter Systems with Tunable Properties. Langmuir 2013, 29, 9544-9550.

(61) Reddy, A.; Sharma, A.; Srivastava, A. Optically Transparent Hydrogels from an Auxin-Amino-Acid Conjugate Super Hydrogelator and its Interactions with an Entrapped Dye. Chem. - Eur. J. 2012, 18, $7575-7581$.

(62) Orfi, L.; Lin, M.; Larive, C. K. Measurement of SDS MicellePeptide Association Using ${ }^{1} \mathrm{H}$ NMR Chemical Shift Analysis and Pulsed-Field Gradient NMR Spectroscopy. Anal. Chem. 1998, 70, $1339-1345$

(63) Cornwell, D. J.; Daubney, O. J.; Smith, D. K. Photopatterned Multidomain Gels: Multi-Component Self-Assembled Hydrogels Based on Partially Self-Sorting 1,3:2,4-Dibenzylidene-d-sorbitol Derivatives. J. Am. Chem. Soc. 2015, 137, 15486-15492.

(64) Foster, J. S.; Żurek, J. M.; Almeida, N. M. S.; Hendriksen, W. E.; le Sage, V. A. A.; Lakshminarayanan, V.; Thompson, A. L.; Banerjee, R.; Eelkema, R.; Mulvana, H.; Paterson, M. J.; van Esch, J. H.; Lloyd, G. O. Gelation Landscape Engineering Using a Multi-Reaction Supramolecular Hydrogelator System. J. Am. Chem. Soc. 2015, 137, $14236-14239$.

(65) Nebot, V. J.; Ojeda-Flores, J. J.; Smets, J.; Fernández-Prieto, S.; Escuder, B.; Miravet, J. F. Rational Design of Heat-Set and SpecificIon-Responsive Supramolecular Hydrogels Based on the Hofmeister Effect. Chem. - Eur. J. 2014, 20, 14465-14472.

(66) Aufderhorst-Roberts, A.; Frith, W. J.; Kirkland, M.; Donald, A. M. Microrheology and Microstructure of Fmoc-Derivative Hydrogels. Langmuir 2014, 30, 4483-4492. 